\title{
OPTIMAL INVENTORY STRATEGIES FOR AN IMPERFECT PRODUCTION SYSTEM WITH ADVERTISEMENT AND PRICE RELIANT DEMAND UNDER REWORK OPTION FOR DEFECTIVES
}

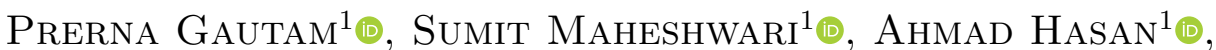 \\ AmRina KaUsaR ${ }^{2}$ AND ChandRA K. JAGGI ${ }^{1, *}$
}

\begin{abstract}
Every industrial sector emits carbon emissions during production, which is always a major concern for environmental practitioners. To resolve this, innovative and smart ways are required that are not only cost-effective but also environmentally savvy. Moreover, the production processes are also prone to various imperfections, and thus the production of defectives is quite pragmatic. The handling of such defective products varies from industry to industry and type of products. The present study constructs an inventory model to handle the defective products via a proficient rework strategy that makes the product fit to be sold at the primary price. Here, the demand for the product is assumed to be dependent on the selling price and advertisements. The model also considers the energy usage during the production and the cost of carbon emissions while optimizing the production batch size and selling price. Optimality is proved graphically by using the software Mathematica 11.3.0. A comprehensive sensitivity analysis for all the parameters is performed to impart managerial insights and robustness to the model.
\end{abstract}

Mathematics Subject Classification. 90B05, 90B30.

Received June 26, 2021. Accepted December 16, 2021.

\section{INTRODUCTION}

The issue of environmental sustainability has become an important area in the supply chain (SC) across the globe. This is attributed to the burgeoning nature of industrialization, public awareness, and the dire effect of manufacturing activities contributing to global warming and other environmental issues. The leading cause of global warming is carbon emission, which is quite harmful to the world. Excessive pollution released by the manufacturing industry must be managed to prevent the adverse impacts of global warming. The government's legislation is carbon cap and trade, which has successfully reduced carbon emissions emitted during industrial activities. To contribute towards a sustainable way of working, it is essential to curb the release of harmful gases into the environment.

Keywords. Inventory, production, energy, pricing, optimization.

1 Department of Operational Research, Faculty of Mathematical Sciences, University of Delhi, Delhi 110007, India.

2 Department of Management Studies, Shaheed Sukhdev College of Business Studies, University of Delhi, Delhi 110089, India.

*Corresponding author: ckjaggi@yahoo.com 
Nowadays, customers are very quality conscious and not ready to accept any defective products which forced the manufacturers to monitor their production process proactively more closely and screen the items before it reaches to its customers. The producers need to continually update their quality levels so that they can sustain themselves in a competitive market. Academicians and practitioners have shown enormous interest in exploring the field of inventory management with imperfect quality items. Harris [22] and Taft [55] first established EOQ and EPQ models for inventory management, respectively. The impact of imperfect quality items in inventory management was studied by numerous researchers. Initially, Porteus [44] and Rosenblatt and Lee [46] explored the effect of imperfect quality items on the fundamental inventory replenishment and production models. Porteus [44] proposed an inventory model in which the production process could get out of control with a certain probability. When the system gets out of control, any future product will be defective and must be reworked before the end of the cycle. Later, Tayi and Ballou [58], Lee [33], examined the reprocessing of the imperfect items in inventory management. It is a well-known fact that manufacturing processes are imperfect, thus, they need to be handled efficiently for the overall sustainability of the business. Currently, the researchers are developing the EPQ/EOQ models under imperfect production and rework plans. These inventory models are used in many practical circumstances because of their applicability. The study of Rosenblatt and Lee [46] suggested that the lot size must be increased, with an increase in the imperfect quality items. Lee et al. [34], Salameh and Jaber [51], and Glock and Jaber [18] developed EPQ models for the imperfect production without noticing the rework perspective. Cárdenas-Barrón [5], and Eroglu and Ozdemir [14] considered shortages in their model to the advancement of this field. Further, Tai [56] claimed that perfect items can deteriorate and this could also be the case with imperfect quality items. Choudhury et al. [8] supposed that the cost of production depends on the reliability parameters of the goods. The considerable inspection time for the imperfect process with a rework is given by Moussawi-Haidar et al. [42]. Further, Kang et al. [25] established a model for the inventory of faulty goods in the work process. The production of defectives can be reduced by applying quality control techniques. Gautam et al. [15] proposed defect management techniques for the imperfect quality items with integrated and Stackelberg decision-making approaches. Khanna et al. [28] developed an integrated model incorporating maintenance and warranty policy for an imperfect production system. Kishore et al. [30] developed an imperfect production model with a two-way inspection plan and rework of imperfect items. Rout et al. [48] proposed a sustainable supply chain model with imperfect production and other pragmatic scenarios viz. deterioration and carbon emissions. Guchhait et al. [21] developed an imperfect production model considering process quality improvement, warranty and shortages. Recently, Gautam et al. [17] developed a two-decade systematic literature review on imperfect quality items taking into account the Scopus database.

Moreover, every manufacturing sector, while producing and holding inventory releases, carbon emissions. The ecological catastrophe allowed scientists to integrate their models to incorporate environmental factors. In this context, a number of researchers have contributed to energy-efficient models. Energy usage in the manufacturing process is quite obvious (Mouzon et al., [43]). The energy consumption was studied by various researchers viz. Bunse et al., [4]; Biel and Glock, [3]; Marchi et al., [37]; etc. Marchi et al. [38] studied a supply chain problem with carbon emissions and energy usage. In the same year, Marchi et al. [38] proposed an energy-efficient model with learning in production. The cap-and-trade regulation was investigated by Purohit et al. [45] and Xu et al. [61]. Tang et al. [57] studied the customer accountable behavior towards the atmosphere. The issue of carbon emission was extensively addressed by some of the remarkable studies viz. Zhu et al. [62], Tiwari et al. [59], Modak et al. [40]. Rout et al., [47], Manna et al., [36], and Rout et al., [48] focused on the effect of carbon emission on the EPQ models. Furthermore, Mishra et al. [39] emphasized on a suitable inventory system with consideration of deterioration and carbon emission.

In the present competitive business environment, advertisement is a way to promote the brand knowledge of the product among the consumers. Depending upon the kind of product and service being offered to the consumers the manufacturer or retailer or both actively contribute towards the advertisement. Further, the price of the item is one of the prominent factors that influence the consumer's preference. Kotler [31] integrated marketing strategies with inventory decisions. Ladany and Sternleib [32] elaborated on the impact of price changes on demand and ordering policy. The effect of price change and advertisements on the demand was 
TABLE 1. Literature review table to fill the study gap.

\begin{tabular}{|c|c|c|c|c|c|c|c|}
\hline \multirow[t]{2}{*}{ Papers } & \multicolumn{2}{|c|}{ Demand function } & \multirow{2}{*}{$\begin{array}{l}\text { Imperfect } \\
\text { production }\end{array}$} & \multirow[t]{2}{*}{ Rework } & \multirow{2}{*}{$\begin{array}{l}\text { Quality } \\
\text { inspection }\end{array}$} & \multirow{2}{*}{$\begin{array}{l}\text { Carbon } \\
\text { emission }\end{array}$} & \multirow{2}{*}{$\begin{array}{l}\text { Energy } \\
\text { usage }\end{array}$} \\
\hline & $\begin{array}{l}\text { Price } \\
\text { dependent }\end{array}$ & $\begin{array}{l}\text { Advertisement } \\
\text { dependent }\end{array}$ & & & & & \\
\hline $\begin{array}{l}\text { Bhunia and } \\
\text { Maiti [2] }\end{array}$ & Yes & Yes & No & No & No & No & No \\
\hline $\begin{array}{l}\text { Ben-Daya and } \\
\text { Hariga [1] }\end{array}$ & No & No & Yes & No & Yes & No & No \\
\hline $\begin{array}{l}\text { Salameh and } \\
\text { Jaber [51] }\end{array}$ & No & No & Yes & No & Yes & No & No \\
\hline $\begin{array}{l}\text { Hayek and } \\
\text { Salameh [23] }\end{array}$ & No & No & Yes & Yes & Yes & No & No \\
\hline $\begin{array}{l}\text { Chung and } \\
\text { Hou }[9]\end{array}$ & No & No & Yes & No & Yes & No & No \\
\hline Chiu [6] & No & No & Yes & Yes & Yes & No & No \\
\hline Chiu et al. [7] & No & No & Yes & Yes & Yes & No & No \\
\hline Sana [52] & No & No & Yes & No & Yes & No & No \\
\hline $\begin{array}{l}\text { Moussawi- } \\
\text { Haidar et al. } \\
{[42]}\end{array}$ & No & No & Yes & Yes & Yes & No & No \\
\hline $\begin{array}{l}\text { Khanna et al. } \\
{[26]}\end{array}$ & No & No & Yes & No & Yes & No & No \\
\hline $\begin{array}{l}\text { Tiwari et al. } \\
\text { [59] }\end{array}$ & No & No & Yes & No & Yes & Yes & No \\
\hline $\begin{array}{l}\text { Khedlekar } \\
\text { and Tiwari } \\
{[29]}\end{array}$ & No & No & Yes & Yes & Yes & No & No \\
\hline $\begin{array}{l}\text { Khanna et al. } \\
{[27]}\end{array}$ & No & No & Yes & Yes & Yes & Yes & No \\
\hline $\begin{array}{l}\text { Ruidas et al. } \\
{[50]}\end{array}$ & Yes & No & Yes & Yes & Yes & Yes & No \\
\hline $\begin{array}{l}\text { De-la-Cruz- } \\
\text { Márquez } \\
\text { et al. }[13]\end{array}$ & Yes & No & Yes & No & Yes & Yes & No \\
\hline Present paper & Yes & Yes & Yes & Yes & Yes & Yes & Yes \\
\hline
\end{tabular}

further investigated by Subramanyam and Kumaraswamy [54], Urban [60], Goyal and Gunasekaran [20], Luo [35]. Bhunia and Maiti [2], Mondal et al. [41] focused on the demand function, which is reliant on price and advertisements. Varying demand models were explored by various researchers; for instance, Glock et al. [19] studied the impact of quality and price on the demand function. Shah et al. [53], Ruidas et al. [49] developed an EPQ model under the price and stock dependent demand function. Dey et al. [11] developed an integrated model with discrete setup cost reduction and selling price-dependent demand. Khanna et al. [27] proposed an EPQ model with the consideration of price-sensitive demand. Further, Dari and Sani [10] utilized the quadratic demand function for the EPQ model. In the same year, Gautam et al. [16] developed a sustainable production model with price-dependent demand. Recently, Dey et al. [12] developed a model for a smart manufacturing system with advertisement-dependent demand. Table 1 summarizes the previous studies that explored the inventory systems under different scenarios. 
Currently, production planning has become one of the key aspects of the company's competitive orientation. To improve the business, the company must carefully design the production process. Excessive or insufficient product coverage will lead to a great loss to the company. Also, no production process is defect-free. The reasons for imperfect production could be an assignable cause such as inferior raw materials, unskilled operators, and machinery disruption. The management needs to closely monitor the process for its output. The defective items if produced should be separated from the good quality items. Further, to minimize the loss due to imperfect production items must be categorized into reworkable and scraps. A lot of researchers have developed inventory models with imperfect production where they classified the items as defective or non-defective. Defective items can be managed depending on the organizational infrastructure. In order to explore the rework option for imperfect quality items, the present study develops an inventory production model with a selling price and advertisement-dependent demand function. The model also incorporates the cost of carbon emission and energy usage. Intending to maximize the total expected profit, the model determines the optimal value of the selling price and the production batch size. The flow of the rest of the manuscript is as follows: the second section gives the nomenclature and assumptions for the mathematical models. The third section develops the mathematical model for the considered problem. Numerical and sensitivity analysis is presented in Sections 4 and 5, respectively. Concluding remarks have been presented in Section 6 .

\section{NOMENCLATURE AND ASSUMPTIONS}

\subsection{Nomenclature}

All the necessary notations are given below;

$\gamma$ : Rate of producing items (/ unit time)

$\gamma_{1}$ : Rate of reworking (/ unit time)

$c$ : Cost of manufacturing per unit

$\beta$ : Rate of producing imperfect items per unit time

$\beta_{1}$ : Cost of screening goods during production (per item)

$\beta_{2}$ : Cost of screening (per item) after the completion of goods production

$H$ : Inventory carrying cost (/unit/unit time)

$H_{1}$ : Inventory carrying cost of imperfect items that are reworked (/unit/unit time)

$C_{S}$ : Setup cost (fixed)

$p$ : Random fraction of imperfect goods

$f(p)$ : Density function of $p$

$s_{p}$ : Price of perfect goods, $s_{p}>z(/$ unit $)$

$t_{1}$ : Manufacturing time, $t_{1}=Q / \gamma$.

$t_{2}$ : Time to inspect.

$T$ : Manufacturing cycle

$c_{r}$ : Cost of rework per unit

$p_{e}$ : Emission cost due to goods production

$w_{e}$ : Emission cost due to storage (\$/unit/year)

$x$ : Inspection rate (/unit/unit time)

$Q$ : Production batch size (/ cycle)

$C_{e}$ : Energy consumption cost $(\$ / \mathrm{kWh})$

$\rho$ : Conversion factor of time unit into hours

\subsection{Assumptions}

The assumptions are given as 

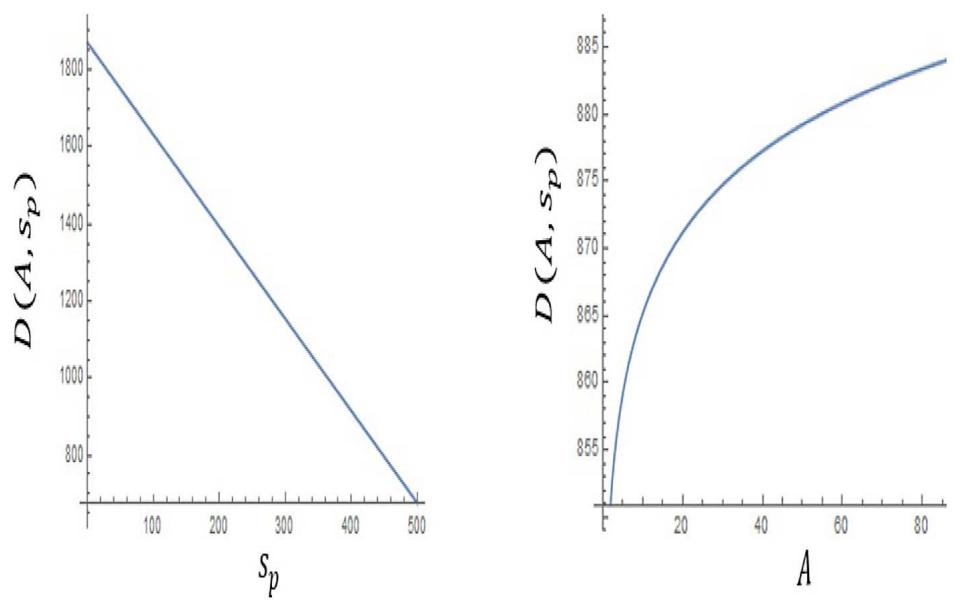

FiguRE 1. Demand graphs with respect to price and advertising.

- The demand rate is defined to be a function of price and advertisement such as $D\left(A, s_{p}\right)=A^{\lambda}\left(a-b s_{p}\right)$, where $s_{p}$ is the selling price and $A$ is frequency of advertisement $a, b, \lambda \geq 0$. Figure 1 shows the demand graphs with respect to price and advertising.

- The relation between the production rate and demand rate is defined as follows: $\gamma>D\left(A, s_{p}\right)$.

- Cost of screening is higher during the manufacturing as compared to after manufacturing, i.e., $\beta_{1}>\beta_{2}$.

- Demand is fulfilled through good items only.

- The relation between screening rate and demand rate is defined as follows: $x>D\left(A, s_{p}\right)$.

- Inventory carrying cost of defective items that are reworked is more than the perfect goods.

- Carbon emission occurs when the products are manufactured and stored.

\section{Mathematical MODEL}

This model considers the production rate $\gamma$ during the time $t_{1}$, in which demand meets from the perfect quality of goods. The rate of screening is higher than the demand rate, so only the perfect quality of items goes to the customers. The production of the items stopped at end of the time $t_{1}$ and during time $t_{1}$, all the items cannot be screened so the remaining items are screened during time $t_{2}$. After time $t_{1}$, the remaining unscreened units are screened to find the imperfect goods for the rework. All the imperfect items are reworked during the time $t_{3}$. The imperfect items are assumed to be reworked at the rate $\gamma_{1}$, with $\gamma_{1}<D\left(A, s_{p}\right)$. The length of time for reworking all the imperfect items is $t_{3}$. After the completion of the reworking process, the reworked items are included in the inventory to satiate the demand during $t_{4}$. Let $\mathrm{p}$ be the proportion of defective items out of the whole production. The manufacturing rate of imperfect goods, $\beta$ can be expressed as

$$
\beta=\gamma p .
$$

Also, $H_{1}$ is the inventory carrying cost of imperfect items being reworked, $H_{1}>H$, and $c_{r}$ is the reworking cost.

The behavior of the on-hand inventory of goods is shown in Figure 2. Equation (3.2) represents the cycle time which is the summation of the time involved in the different processes such as production time, inspection time after production, rework time, and production downtime.

$$
T=t_{1}+t_{2}+t_{3}+t_{4}
$$




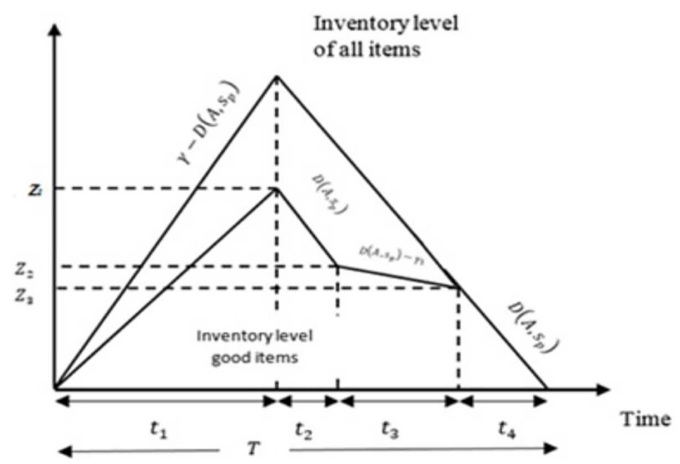

FIGURE 2. Inventory representation over time when imperfect items are reworked.

During the production, the demand is met by the perfect quality items only. Equation (3.3) represents the total count of screened units during inspection:

$$
\frac{D\left(A, s_{p}\right) t_{1}}{(1-p)}
$$

When the production system stopped, it is found that the units of defective items is given as

$$
\frac{D\left(A, s_{p}\right) t_{1}}{1-p}-D\left(A, s_{p}\right) t_{1}=\frac{D\left(A, s_{p}\right) Q}{\gamma}\left(\frac{p}{1-p}\right) \text {. }
$$

The uninspected inventory during $t_{1}$ will be

$$
Q\left(1-\frac{D\left(A, s_{p}\right)}{\gamma}\right)-\frac{D\left(A, s_{p}\right) Q}{\gamma}\left(\frac{p}{1-p}\right) .
$$

Time to inspect the remaining uninspected inventory:

$$
t_{2}=\frac{Q\left(1-\frac{D\left(A, s_{p}\right)}{\gamma}\right)-Q\left(p D\left(A, s_{p}\right) /(\gamma(1-p))\right)}{x} .
$$

$z_{1}$ is the maximum inventory level of on-hand inventory of good items in units, when the production process ends.

$$
t_{1}=\frac{Q}{\gamma}=\frac{z_{1}}{\gamma-\beta-D\left(A, s_{p}\right)}
$$

where,

$$
z_{1}=Q\left(1-\frac{D\left(A, s_{p}\right)}{\gamma}-\frac{\beta}{\gamma}\right) .
$$

$z_{2}$ is the inventory level of good items when the screening during $t_{2}$ ends.

$$
\begin{gathered}
z_{2}=z_{1}-D\left(A, s_{p}\right) t_{2} \\
=Q\left[\left(1-\frac{D\left(A, s_{p}\right)}{\gamma}-\frac{\beta}{\gamma}\right)-\frac{D\left(A, s_{p}\right)}{x}\left(1-\frac{D\left(A, s_{p}\right)}{\gamma}-\frac{p D\left(A, s_{p}\right)}{\gamma(1-p)}\right)\right] .
\end{gathered}
$$

All the defective products have been reworked in the time period $t_{3}$. At the completion of $t_{3}$, the reworked goods are added to the inventory in order to satiate the demand in $t_{4}$. Assume $\beta$ is the manufacturing rate 

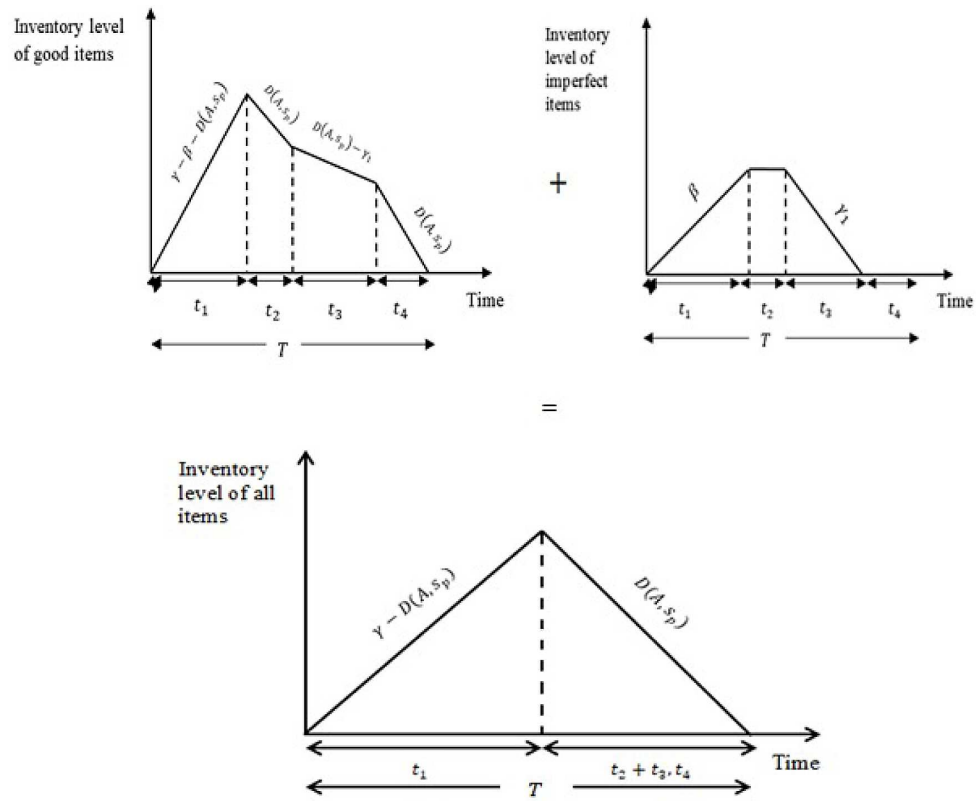

FiguRE 3. Inventory level of imperfect and all types of items.

for the imperfect items, that can be expressed in the term of manufacturing rate and the proportion of the defectives such as $\beta=p \gamma$. From Figure 3, it is clear that the $t_{3}$ is the time for the rework of the defective goods which is given below in the equation (3.10);

$$
t_{3}=\frac{p Q}{\gamma_{1}}=\frac{\beta Q}{\gamma \gamma_{1}}
$$

$t_{4}$ is the time between the completing the rework and the end of cycle time i.e., $t_{4}=z_{3} / D\left(A, s_{p}\right)$, where, $z_{3}$ is the good items inventory, after the completion of rework process and it is obtained as:

$$
\begin{gathered}
z_{3}=z_{2}-\left(D\left(A, s_{p}\right)-\gamma_{1}\right) t_{3} \\
=Q\left[\left(1-p-\frac{D\left(A, s_{p}\right)}{\gamma}\right)-\frac{D\left(A, s_{p}\right)}{x}\left(1-\frac{D\left(A, s_{p}\right)}{\gamma}\left(\frac{1}{1-p}\right)\right)-\frac{\left(D\left(A, s_{p}\right)-\gamma_{1}\right) \beta}{\gamma_{1}}\right] .
\end{gathered}
$$

\subsection{Energy consumption}

While managing the SC, energy is used during manufacturing, distribution, conservation of goods, and other activities. Out of all these processes of the SC, the energy consumption is highest during manufacturing. The energy consumption in the production process depends mainly on the performance and the time usage by the machine. The usage of machines is sometimes divided between the various region with a different level of energy consumption associated with each state (Jeon et al., [24]). The overall performance of the machine in the production process can be calculated as,

$$
\text { Energy Consumption }=\sum_{i=1}^{N} \text { Power }_{i} \times \text { Time }_{i} .
$$


In this study, the production process and rework process are considered. The required power by the two different processes are $P_{p}$ and $P_{r}$, in $\mathrm{kW}$, whereas the time taken to perform production and rework is $t_{p}$ and $t_{r}$, where,

$$
\begin{aligned}
& t_{p}=t_{1}=\frac{Q}{\gamma}=\frac{z_{1}}{\gamma-\beta-D\left(A, s_{p}\right)} \\
& t_{r}=t_{3}=\frac{p Q}{\gamma_{1}}
\end{aligned}
$$

$$
\text { Cost of energy consumption per cycle }=C_{e} \rho\left\{\frac{P_{p} Q}{\gamma}+\frac{P_{r} p Q}{\gamma_{1}}\right\}
$$

where, $C_{e}$ is the cost of energy consumptions per unit $(\mathrm{kWh})$ and $\rho$ is the conversion factor of time units into hours.

The total cost incurred is given as:

$$
\begin{aligned}
T C\left(Q, s_{p}\right)= & C_{s}+\left(c+p_{e}\right) Q+c_{r} p Q+\beta_{1} \frac{D\left(A, s_{p}\right)}{(1-p)} \frac{Q}{\gamma}+\beta_{2} Q\left[1-\frac{D\left(A, s_{p}\right)}{\gamma}\left(\frac{1}{1-p}\right)\right] \\
& +C_{e} \rho\left\{\frac{P_{p} Q}{\gamma}+\frac{P_{r} p Q}{\gamma_{1}}\right\}+\left(H_{1}+w_{e}\right) \frac{\gamma_{1} t_{3}^{2}}{2} \\
& +\left(H+w_{e}\right)\left[\frac{z_{1} t_{1}}{2}+\frac{\left(z_{1}+z_{2}\right) t_{2}}{2}+\frac{\left(z_{2}+z_{3}\right) t_{3}}{2}+\frac{z_{3} t_{4}}{2}+\frac{t_{1}^{2} \beta}{2}+t_{1} t_{2} \beta\right] .
\end{aligned}
$$

The revenue is obtained by the sale of perfect and reworked goods, which is ultimately the sales on total produced quantity. Thus, the total profit per cycle would be:

$$
\begin{aligned}
T P\left(Q, s_{p}\right)= & s_{p} Q-\left[C_{s}+\left(c+p_{e}\right) Q+c_{r} p Q+\beta_{1} \frac{D\left(A, s_{p}\right)}{(1-p)} \frac{Q}{\gamma}+\beta_{2} Q\left\{1-\frac{D\left(A, s_{p}\right)}{\gamma}\left(\frac{1}{1-p}\right)\right\}\right] \\
& -\left(H+w_{e}\right)\left[\frac{z_{1} t_{1}}{2}+\frac{\left(z_{1}+z_{2}\right) t_{2}}{2}+\frac{\left(z_{2}+z_{3}\right) t_{3}}{2}+\frac{z_{3} t_{4}}{2}+\frac{t_{1}^{2} \beta}{2}+t_{1} t_{2} \beta\right] \\
& -\left(H_{1}+w_{e}\right) \frac{\gamma_{1} t_{3}^{2}}{2}-C_{e} \rho\left\{\frac{P_{p} Q}{\gamma}+\frac{P_{r} p Q}{\gamma_{1}}\right\} .
\end{aligned}
$$

By employing the renewal reward theorem, the expected profit per unit time would be:

$$
\operatorname{ETPU}\left(Q, s_{p}\right)=\frac{\operatorname{ETP}\left(Q, s_{p}\right)}{E(T)}
$$

where, $E(T)=Q / D\left(A, s_{p}\right)$ is the expected time of production.

$$
\begin{gathered}
\operatorname{ETPU}\left(Q, s_{p}\right)=s_{p} D\left(A, s_{p}\right)-C_{s} \frac{D\left(A, s_{p}\right)}{Q}-\left(c+p_{e}\right) D\left(A, s_{p}\right)-c_{r} D\left(A, s_{p}\right) E(p) \\
-\frac{\beta_{1}\left(D\left(A, s_{p}\right)\right)^{2} Q}{\gamma} E\left(\frac{1}{1-p}\right)-\beta_{2} D\left(A, s_{p}\right)\left[1-\frac{D\left(A, s_{p}\right)}{\gamma} E\left(\frac{1}{1-p}\right)\right] \\
-\left(H+w_{e}\right) D\left(A, s_{p}\right) Q\left[\frac{1}{2 \gamma}\left(1-\frac{D\left(A, s_{p}\right)}{\gamma}\right)-\frac{1}{2 x}\left(1-E(p)-\frac{D\left(A, s_{p}\right)}{\gamma}\right)\left(1-\frac{D\left(A, s_{p}\right)}{\gamma} E\left(\frac{1}{1-p}\right)\right)\right. \\
+\frac{1}{2 x}\left\{\left(1-E(p)-\frac{D\left(A, s_{p}\right)}{\gamma}\right)-\frac{D\left(A, s_{p}\right)}{x}\left(1-\frac{D\left(A, s_{p}\right)}{\gamma} E\left(\frac{1}{1-p}\right)\right)\right\}\left(1-\frac{D\left(A, s_{p}\right)}{\gamma} E\left(\frac{1}{1-p}\right)\right) \\
+\frac{E(p)}{D\left(A, s_{p}\right)}\left\{\left(1-E(p)-\frac{D\left(A, s_{p}\right)}{\gamma}\right)-\frac{D\left(A, s_{p}\right)}{x}\left(1-\frac{D\left(A, s_{p}\right)}{\gamma} E\left(\frac{1}{1-p}\right)\right)\right\}+\frac{E(p)}{x}\left(1-\frac{D\left(A, s_{p}\right)}{\gamma} E\left(\frac{1}{1-p}\right)\right)
\end{gathered}
$$




$$
\begin{gathered}
+\frac{1}{2 D\left(A, s_{p}\right)}\left\{E\left(p^{2}\right)-2 E(p)\left(1-\frac{D\left(A, s_{p}\right)}{\gamma}\right)-\frac{2\left(D\left(A, s_{p}\right)\right)^{3}}{x^{2} \gamma} E\left(\frac{1}{1-p}\right)+\frac{\left(D\left(A, s_{p}\right)\right)^{4}}{x^{2} \gamma^{2}} E\left(\frac{1}{1-p}\right)^{2}\right\} \\
\left.-\frac{\left(D\left(A, s_{p}\right)-\gamma_{1}\right) E\left(p^{2}\right)}{2 D\left(A, s_{p}\right) \gamma_{1}}+\frac{1}{2 D\left(A, s_{p}\right)}\left\{\left(1-\frac{D\left(A, s_{p}\right)}{\gamma}\right)^{2}+\frac{\left(D\left(A, s_{p}\right)\right)^{2}}{x^{2}}\right\}\right] \\
-\left(H_{1}+w_{e}\right) \frac{E\left(p^{2}\right) D\left(A, s_{p}\right) Q}{2 \gamma_{1}}-C_{e} \rho D\left(A, s_{p}\right)\left\{\frac{P_{p}}{\gamma}+\frac{P_{r} E(p)}{\gamma_{1}}\right\}
\end{gathered}
$$

\subsection{Concavity of the profit function}

This section presents the optimality of the objective function:

Necessary Conditions:

$$
\begin{gathered}
\frac{\partial E T P U\left(Q, s_{p}\right)}{\partial Q}=0 \\
\frac{\partial E T P U\left(Q, s_{p}\right)}{\partial s_{p}}=0 \\
\frac{\partial E T P U\left(Q, s_{p}\right)}{\partial Q}=0 \\
Q^{*}=\sqrt{\left.\frac{\frac{\left(H_{1}+w_{e}\right) D\left(A, s_{p}\right) E(p)^{2}}{2 \gamma_{1}}+\left(H+w_{e}\right)}{\left.\frac{D\left(A, s_{p}\right)}{\gamma}\left(1-\frac{D\left(A, s_{p}\right)}{\gamma}\right)+\frac{1}{2}\left\{\left(1-\frac{D\left(A, s_{p}\right)}{\gamma}\right)^{2}+\frac{\left(D\left(A, s_{p}\right)\right)^{2}}{x^{2}}\right\}\right]}-\frac{D\left(A, s_{p}\right) A_{2}^{2}}{2 x}+E(p)\left(A_{1}-\frac{D\left(A, s_{p}\right) A_{2}}{x}\right)+\frac{D\left(A, s_{p}\right) E(p) A_{2}}{x}+A_{3}\right]}
\end{gathered}
$$

where,

$$
\begin{gathered}
A_{1}=1-E(p)-\frac{D\left(A, s_{p}\right)}{\gamma} \\
A_{2}=1-\frac{D\left(A, s_{p}\right)}{\gamma} E\left(\frac{1}{1-p}\right) \\
A_{3}=\frac{1}{2}\left[\begin{array}{l}
E\left(p^{2}\right)-2 E(p)\left(1-\frac{D\left(A, s_{p}\right)}{\gamma}\right)-2 \frac{\left(D\left(A, s_{p}\right)\right)^{3}}{x^{2} \gamma} E\left(\frac{1}{1-p}\right) \\
+\frac{\left(D\left(A, s_{p}\right)\right)^{4}}{x^{2} \gamma^{2}} E\left(\frac{1}{(1-p)^{2}}\right)-\frac{\left(D\left(A, s_{p}\right)-\gamma_{1}\right) E\left(p^{2}\right)}{2 \gamma_{1}}
\end{array}\right]
\end{gathered}
$$

The sufficient condition for the optimum value of the profit function depends on the minors of the Hessian matrix $H$,

$$
H=\left[\begin{array}{ll}
\frac{\partial^{2} E T P U\left(Q, s_{p}\right)}{\partial Q^{2}} & \frac{\partial^{2} E T P U\left(Q, s_{p}\right)}{\partial Q \partial s_{p}} \\
\frac{\partial^{2} E T P U\left(Q, s_{p}\right)}{\partial s_{p} \partial Q} & \frac{\partial^{2} E T P U\left(Q, s_{p}\right)}{\partial s_{p}{ }^{2}}
\end{array}\right]
$$

where, $D_{1}\left(Q, s_{p}\right)<0, D_{2}\left(Q, s_{p}\right)>0$, this condition must be satisfied for the optimality of the function.

$$
\begin{aligned}
& D_{1}=\frac{\partial^{2} E T P U\left(Q, s_{p}\right)}{\partial Q^{2}} \\
& D_{2}=\operatorname{det} H=\left[\begin{array}{ll}
\frac{\partial^{2} E T P U\left(Q, s_{p}\right)}{\partial Q^{2}} & \frac{\partial^{2} E T P U\left(Q, s_{p}\right)}{\partial Q \partial s_{p}} \\
\frac{\partial^{2} E T P U\left(Q, s_{p}\right)}{\partial s_{p} \partial Q} & \frac{\partial^{2} E T P U\left(Q, s_{p}\right)}{\partial s_{p}{ }^{2}}
\end{array}\right]
\end{aligned}
$$




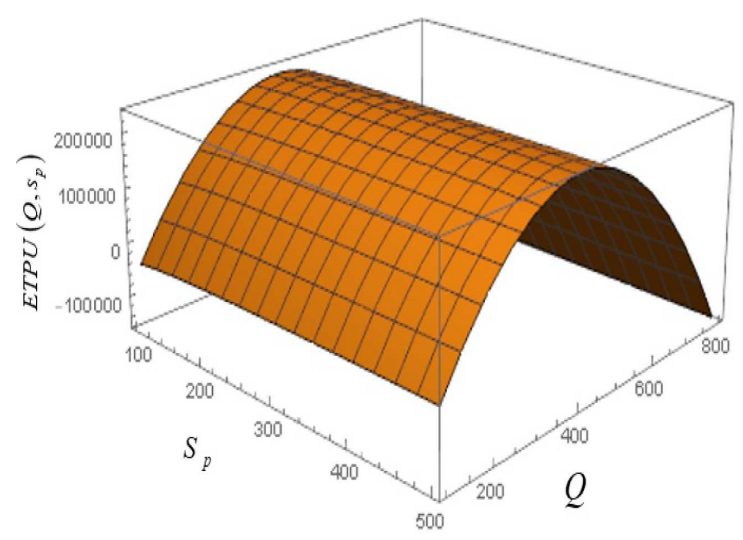

Figure 4. Profit vs. $Q$ And $S_{p}$.

TABLE 2. Data for the numerical example.

\begin{tabular}{lccccc}
\hline \hline Parameter & Value & Parameter & Value & Parameter & Value \\
\hline$\gamma$ & 1600 units/year & $\beta_{1}$ & $\$ 0.5$ & $a$ & 1800 \\
$\rho$ & 8760 & $\beta_{2}$ & $\$ 0.6$ & $b$ & 2.5 \\
$c$ & $\$ 104$ & $c_{s}$ & $\$ 1500$ & $p_{e}$ & $6 \$ /$ unit \\
$x$ & 175200 unit & $H$ & $\$ 20 /$ unit/year & $w_{e}$ & $4 \$ /$ unit \\
$P_{p}$ & $1.5 \mathrm{~kW}$ & $P_{r}$ & $2 \mathrm{~kW}$ & $H_{1}$ & $\$ 22 /$ unit $/$ year \\
$c_{r}$ & $8 \$$ unit & $\gamma_{1}$ & 100 units/year & $\lambda$ & 0.01 \\
$A$ & 50 & $C_{e}$ & $0.5 / \mathrm{kWh}$ & & \\
\hline
\end{tabular}

The minor of the Hessian matrix has been shown by $D_{1}$ and $D_{2}$.

It is very difficult to establish the sufficiency conditions mathematically, therefore, the concavity of the objective function is established graphically as in Figure 4 with the help of Mathematica 11.3.0 software.

\section{Numerical EXAMPLE}

Table 2 gives the value of parameters used to perform the numerical analysis. The fraction of imperfect items is uniformly distributed over $[0,0.1]$ with p.d.f. as:

$$
f(p)=\left\{\begin{array}{ll}
10 & \text { for } 0 \leq \mathrm{p} \leq 0.1 \\
0 & \text { Otherwise }
\end{array} .\right.
$$

Utilizing (4.1), $E(p)=0.05, E\left(p^{2}\right)=0.0033, E\left(\frac{1}{1-p}\right)=1.0536, E\left(\frac{p}{1-p}\right)=0.0536$ and $E\left(\frac{1}{1-p}\right)^{2}=1.1111$.

The following optimal results are obtained:

The optimal value of selling price $s_{p}=419.12 \$$ per unit, optimal quantity $Q=355$ units, and optimal expected profit $\operatorname{ETPU}\left(Q, s_{p}\right)=\$ 227804.81$.

\section{Sensitivity ANALYSiS}

In this section, the model is examined for its robustness by changing the key parameters viz. holding costs of the perfect item $(H)$, Holding cost of imperfect items that are reworked $\left(H_{1}\right)$, screening cost dur- 
TABLE 3. Sensitivity analysis with respect to key parameters.

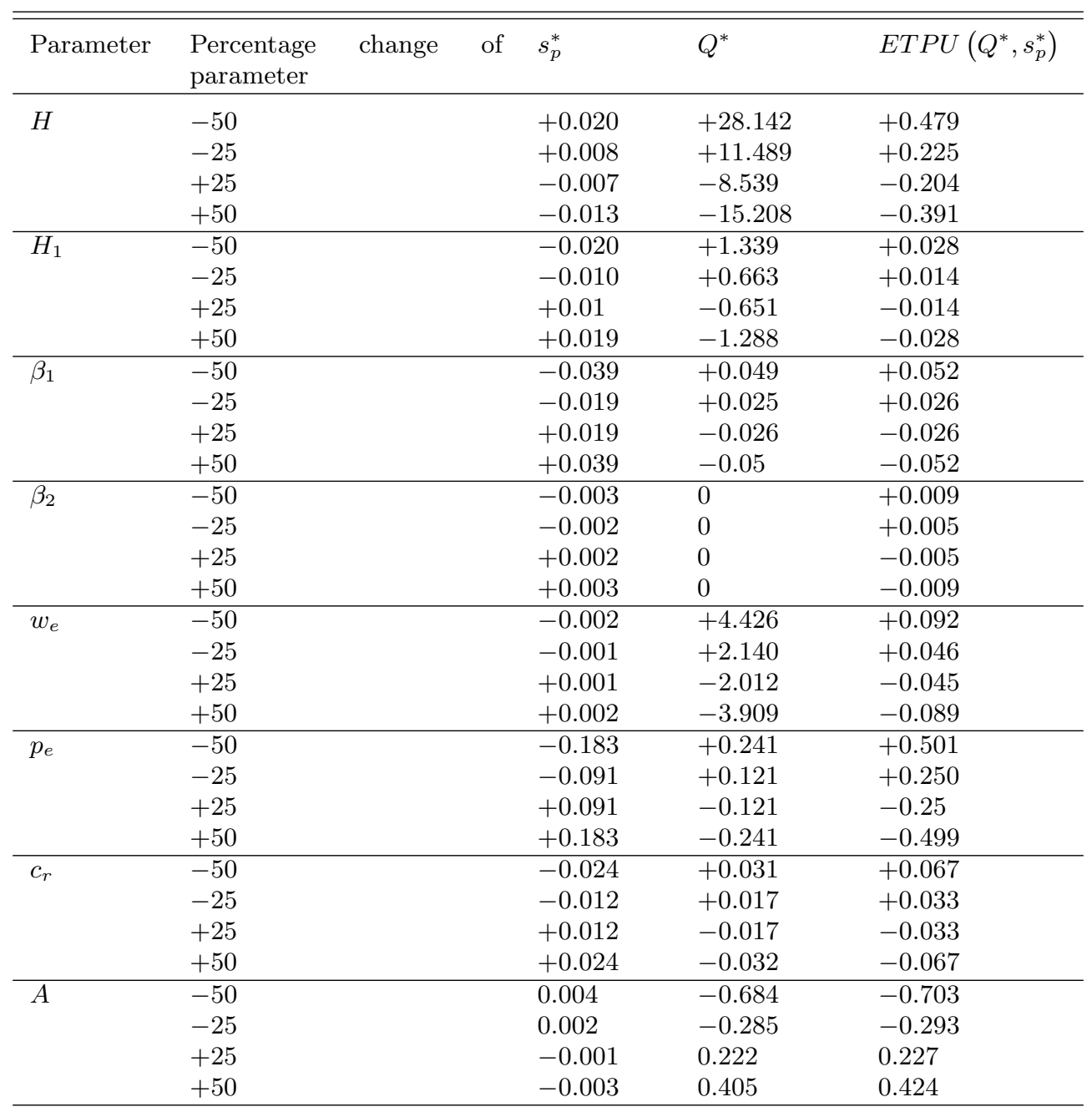

ing production $\left(\beta_{1}\right)$, cost of screening after production $\left(\beta_{2}\right)$, carbon emission cost from holding items in the inventory $\left(w_{e}\right)$, carbon emission cost from producing the goods $\left(p_{e}\right)$, cost of manufacturing per unit $(c)$, rework $\operatorname{cost}\left(c_{r}\right)$, and frequency of advertisements $(A)$. The sensitivity analysis has been presented in Table 3 .

\section{Observations and insights}

Following observations and insights are derived from Table 3:

As the cost of holding upsurges (holding cost for perfect quality items $H$ and reworked items $H_{1}$ ), the production quantity and the total expected profit decrease. Thus, the rising costs of holding indicate that the production quantity needs to be monitored carefully so as to control high wages in holding costs.

Further, as screening cost $\left(\beta_{1}\right)$ during the production and after production $\left(\beta_{2}\right)$ increases, the total profit of the system decreases. It is suggested to review or change the current inspection methods adopted by the manufacturer to curb high screening costs. 
As the carbon-emission cost involved in the production $\left(p_{e}\right)$ and holding of items $\left(w_{e}\right)$ increases the total profit of the system decreases. Higher emissions cost recommends manufacturing only necessary quantities to expurgate on escalating emissions cost.

As the rework cost increases the production quantity and total profit of the system decreases. To deal with increasing rework costs, it is feasible to look for other options to deal with the defective items. The items can be salvaged to a secondary market or they can be sent to a third-party service provided for recycling.

With an increase in the advertisement cost, the selling price decreases, production quantity and profit increase. In such a case it is suggested to the manufacturer to reduce the selling price in order to capture more demand and ultimately fetch more profits.

\section{Conclusion}

Manufacturing systems heavily emit carbon emissions. Therefore, initiatives must be taken by policymakers or government legislation to reduce the emissions of greenhouse gases for sustainable growth. This paper shows how environmental policies can be integrated with the development of sustainable inventory models. The model considers the impact of imperfect quality items and suggests rework options. The key decisions are to regulate the optimal manufacturing quantity and the selling price of the items in an attempt to optimize the total expected profit. The suggested study focuses on the defective production system where defectives are reworked at the manufacturer's end only. The model also considers carbon emissions and energy usage in the production process so as to depict a more pragmatic inventory scenario. The model can be extended to an integrated decision-making model by incorporating the scenario of retailers. The production model proposed in this study could also be extended by implementing disruption in the production process.

\section{APPLICABILITY}

The model applies to a wide variety of manufacturing industries where the products can be sent for a rework process. The model can be well-fitted in the textile, electronics, and allied industries as these products can be reworked subject to reworkable manufacturing defects. Numerous industries are now focusing on reworking options for their defectives as an additional investment towards environmental sustainability.

\section{LIMITATIONS AND DIRECTIONS FOR FUTURE RESEARCH}

The limitation of this research is that the developed study focuses only on the manufacturer's scenario and how the proposed practical setting will impact the total profit of the manufacturer. Therefore, for this research, it would be meaningful to consider the scenario of the supply chain entities that are linked with this manufacturer. The cases can be compared regarding the influence of rework and non-rework decisions at the manufacturer and their impact on the respective supply chain entities. Further, in a pragmatic instance, the information about some parameters is not always precise. So, it would be practical to develop some fuzzy and dynamic research dimensions.

Acknowledgements. All the authors show their gratitude to the editor and anonymous reviewers for their constant support in significantly shaping the manuscript. We also take this opportunity to express our sincere thanks to Mr. Pulkit Srivastava, University of Delhi for his assistance in converting the manuscript in Latex format.

Disclosure statement. No potential conflict of interest was reported by the author(s).

\section{REFERENCES}

[1] M. Ben-Daya and M. Hariga, Economic lot scheduling problem with imperfect production processes. J. Oper. Res. Soc. 51 (2000) 875-881. 
[2] A.K. Bhunia and M. Maiti, An inventory model for decaying items with selling price, frequency of advertisement and linearly time-dependent demand with shortages. IAPQR Trans. 22 (1997) 41-50.

[3] K. Biel and C.H. Glock, Systematic literature review of decision support models for energy-efficient production planning. Comput. Ind. Eng. 101 (2016) 243-259.

[4] K. Bunse, M. Vodicka, P. Schönsleben, M. Brülhart and F.O. Ernst, Integrating energy efficiency performance in production management-gap analysis between industrial needs and scientific literature. J. Clean. Prod. 19 (2011) 667-679.

[5] L.E. Cárdenas-Barrón, Economic production quantity with rework process at a single-stage manufacturing system with planned backorders. Comput. Ind. Eng. 57 (2009) 1105-1113.

[6] Y.P. Chiu, Determining the optimal lot size for the finite production model with random defective rate, the rework process, and backlogging. Eng. Optim. 35 (2003) 427-437.

[7] S.W. Chiu, D.C. Gong and H.M. Wee, Effects of random defective rate and imperfect rework process on economic production quantity model. Jpn. J. Ind. Appl. Math. 21 (2004) 375.

[8] R.R. Choudhury, S.K. Ghosh and K.S. Chaudhuri, The effect of imperfect production in an economic production lot size model. Int. J. Manag. Sci. Eng. Manag. 10 (2015) 288-296.

[9] K.J. Chung and K.L. Hou, An optimal production run time with imperfect production processes and allowable shortages. Comput. Oper. Res. 30 (2003) 483-490.

[10] S. Dari and B. Sani, An EPQ model for delayed deteriorating items with quadratic demand and linear holding cost. Opsearch 57 (2020) 46-72.

[11] B.K. Dey, B. Sarkar, M. Sarkar and S. Pareek, An integrated inventory model involving discrete setup cost reduction, variable safety factor, selling price dependent demand, and investment. RAIRO-Oper. Res. 53 (2019) 39-57.

[12] B.K. Dey, S. Bhuniya and B. Sarkar, Involvement of controllable lead time and variable demand for a smart manufacturing system under a supply chain management. Expert Syst. Appl. 184 (2021) 115464.

[13] C.G. De-la-Cruz-Márquez, L.E. Cárdenas-Barrón and B. Mandal, An inventory model for growing items with imperfect quality when the demand is price sensitive under carbon emissions and shortages. Math. Probl. Eng. (2021) 1-23.

[14] A. Eroglu and G. Ozdemir, An economic order quantity model with defective items and shortages. Int. J. Prod. Econ. 106 (2007) 544-549.

[15] P. Gautam, A. Kishore, A. Khanna and C.K. Jaggi, Strategic defect management for a sustainable green supply chain. J. Clean. Prod. 233 (2019) 226-241.

[16] P. Gautam, A. Khanna and C.K. Jaggi, Preservation technology investment for an inventory system with variable deterioration rate under expiration dates and price sensitive demand. Yugosl. J. Oper. Res. 30 (2020) 289-305.

[17] P. Gautam, S. Maheshwari, A. Kausar and C.K. Jaggi, Inventory models for imperfect quality items: a two-decade review. Adv. Interdiscip. Res. Eng. Business Manag. (2021) 185-215.

[18] C.H. Glock and M.Y. Jaber, Learning effects and the phenomenon of moving bottlenecks in a two-stage production system. Appl. Math. Model. 37 (2013) 8617-8628.

[19] C.H. Glock, M.Y. Jaber and C. Searcy, Sustainability strategies in an EPQ model with price-and quality-sensitive demand. Int. J. Logist. Manag. 23 (2012) 340-359.

[20] S.K. Goyal and A. Gunasekaran, An integrated production-inventory-marketing model for deteriorating items. Comput. Ind. Eng. 28 (1995) 755-762.

[21] R. Guchhait, B.K. Dey, S. Bhuniya, B. Ganguly, B. Mandal, R.K. Bachar, B. Sarkar, H.M. Wee and K. Chaudhuri, Investment for process quality improvement and setup cost reduction in an imperfect production process with warranty policy and shortages. RAIRO-Oper. Res. 54 (2020) 251-266.

[22] F.W. Harris, How many parts to make at once. Fact. Mag. Manag. 10 (1913) 135-136.

[23] P.A. Hayek and M.K. Salameh, Production lot sizing with the reworking of imperfect quality items produced. Prod. Plan. Control. 12 (2001) 584-590.

[24] H.W. Jeon, M. Taisch and V.V. Prabhu, Modelling and analysis of energy footprint of manufacturing systems. Int. J. Prod. Res. 53 (2015) 7049-7059.

[25] C.W. Kang, M. Ullah, B. Sarkar, I. Hussain and R. Akhtar, Impact of random defective rate on lot size focusing work-in-process inventory in manufacturing system. Int. J. Prod. Res. 55 (2017) 1748-1766.

[26] A. Khanna, A. Kishore and C.K. Jaggi, Strategic production modeling for defective items with imperfect inspection process, rework, and sales return under two-level trade credit. Int. J. Ind. Eng. Comput. 8 (2017) 85-118.

[27] A. Khanna, P. Gautam, A. Hasan and C.K. Jaggi, Inventory and pricing decisions for an imperfect production system with quality inspection, rework and carbon-emissions. Yugosl. J. Oper. Res. 30 (2020) 339-360.

[28] A. Khanna, P. Gautam, B. Sarkar and C.K. Jaggi, Integrated vendor-buyer strategies for imperfect production systems with maintenance and warranty policy. RAIRO-Oper. Res. 54 (2020) 435-450.

[29] U.K. Khedlekar and R.K. Tiwari, Imperfect production model for sensitive demand with shortage. Reliab. Theory Appl. 13 (2018) 43-54.

[30] A. Kishore, P. Gautam, A. Khanna and C.K. Jaggi, Investigating the effect of learning on setup cost in imperfect production systems using two-way inspection plan for rework under screening constraints. Sci. Iran. 27 (2020) 3265-3288. 
[31] P. Kotler, Marketing decision making: a model building approach. Holt, Rinehart, and Winston (1972) 23-37.

[32] S. Ladany and A. Sternlieb, The interaction of economic ordering quantities and marketing policies. AIIE Trans. 6 (1974) $35-40$.

[33] H.L. Lee, Lot sizing to reduce capacity utilization in a production process with defective items, process corrections, and rework. Manage. Sci. 38 (1992) 1314-1328.

[34] H.H. Lee, M.J. Chandra and V.J. Deleveaux, Optimal batch size and investment in multistage production systems with scrap. Prod. Plan. Control. 8 (1997) 586-596.

[35] W. Luo, An integrated inventory system for perishable goods with backordering. Comput. Ind. Eng. 34 (1998) 685-693.

[36] A.K. Manna, B. Das and S. Tiwari, Impact of carbon emission on imperfect production inventory system with advance payment base free transportation. RAIRO-Oper. Res. 54 (2020) 1103-1117.

[37] B. Marchi, S. Zanoni, I. Ferretti and L.E. Zavanella, Stimulating investments in energy efficiency through supply chain integration. Energies 11 (2018) 858.

[38] B. Marchi, S. Zanoni and M.Y. Jaber, Economic production quantity model with learning in production, quality, reliability and energy efficiency. Comput. Ind. Eng. 129 (2019) 502-511.

[39] U. Mishra, J.Z. Wu and B. Sarkar, Optimum sustainable inventory management with backorder and deterioration under controllable carbon emissions. J. Clean. Prod. 279 (2021) 123699.

[40] N.M. Modak, D.K. Ghosh, S. Panda and S.S. Sana, Managing green house gas emission cost and pricing policies in a two-echelon supply chain. CIRP J. Manuf. Sci. Technol. 20 (2018) 1-11.

[41] B. Mondal, A.K. Bhunia and M. Maiti, Inventory models for defective items incorporating marketing decisions with variable production cost. Appl. Math. Model. 33 (2009) 2845-2852.

[42] L. Moussawi-Haidar, M. Salameh and W. Nasr, Production lot sizing with quality screening and rework. Appl. Math. Model. 40 (2016) 3242-3256.

[43] G. Mouzon, M.B. Yildirim and J. Twomey, Operational methods for minimization of energy consumption of manufacturing equipment. Int. J. Prod. Res. 45 (2007) 4247-4271.

[44] E.L. Porteus, Optimal lot sizing, process quality improvement and setup cost reduction. Oper. Res. 34 (1986) $137-144$.

[45] A.K. Purohit, R. Shankar, P.K. Dey and A. Choudhary, Non-stationary stochastic inventory lot-sizing with emission and service level constraints in a carbon cap-and-trade system. J. Clean. Prod. 113 (2016) 654-661.

[46] M.J. Rosenblatt and H.L. Lee, Economic production cycles with imperfect production processes. IIE Trans. 18 (1986) $48-55$.

[47] C. Rout, R.S. Kumar, D. Chakraborty and A. Goswami, An EPQ model for deteriorating items with imperfect production, inspection errors, rework and shortages: a type-2 fuzzy approach. Opsearch 56 (2019) 657-688.

[48] C. Rout, A. Paul, R.S. Kumar, D. Chakraborty and A. Goswami, Cooperative sustainable supply chain for deteriorating item and imperfect production under different carbon emission regulations. J. Clean. Prod. 272 (2020) 122170.

[49] S. Ruidas, M.R. Seikh and P.K. Nayak, An EPQ model with stock and selling price dependent demand and variable production rate in interval environment. Int. J. Syst. Assur. Eng. Manag. 11 (2020) 385-399.

[50] S. Ruidas, M.R. Seikh and P.K. Nayak, A production inventory model with interval-valued carbon emission parameters under price-sensitive demand. Comput. Ind. Eng. 154 (2021) 107154.

[51] M.K. Salameh and M.Y. Jaber, Economic production quantity model for items with imperfect quality. Int. J. Prod. Econ. 64 (2000) 59-64.

[52] S.S. Sana, An economic production lot size model in an imperfect production system. Eur. J. Oper. Res. 201 (2010) $158-170$.

[53] N.H. Shah, D.G. Patel and D.B. Shah, EPQ model for returned/reworked inventories during imperfect production process under price-sensitive stock-dependent demand. Oper. Res. 18 (2018) 343-359.

[54] E.-S. Subramanyam and S. Kumaraswamy, EOQ formula under varying marketing policies and conditions. AIIE Trans. 13 (1981) 312-314.

[55] E.W. Taft, The most economical production lot. Iron Age 101 (1918) 1410-1412.

[56] A.H. Tai, Economic production quantity models for deteriorating/imperfect products and service with rework. Comput. Ind. Eng. 66 (2013) 879-888.

[57] J. Tang, S. Ji and L. Jiang, The design of a sustainable location-routing-inventory model considering consumer environmental behavior. Sustainability 8 (2016) 211.

[58] G.K. Tayi and D.P. Ballou, An integrated production-inventory model with reprocessing and inspection. Int. J. Prod. Res. 26 (1988) 1299-1315.

[59] S. Tiwari, Y. Daryanto and H.M. Wee, Sustainable inventory management with deteriorating and imperfect quality items considering carbon emission. J. Clean. Prod. 192 (2018) 281-292.

[60] T.L. Urban, Deterministic inventory models incorporating marketing decisions. Comput. Ind. Eng. 22 (1992) $85-93$. 
[61] J. Xu, Y. Chen and Q. Bai, A two-echelon sustainable supply chain coordination under cap-and-trade regulation. J. Clean. Prod. 135 (2016) 42-56.

[62] L. Zhu, J. Zhou, Y. Yu and J. Zhu, Emission-Dependent Production for Environment-Aware Demand in Cap-and-Trade System. J. Adv. Manuf. Syst. 16 (2017) 67-80.

\section{Subscribe to Open (S20) A fair and sustainable open access model}

This journal is currently published in open access under a Subscribe-to-Open model (S2O). S2O is a transformative model that aims to move subscription journals to open access. Open access is the free, immediate, online availability of research articles combined with the rights to use these articles fully in the digital environment. We are thankful to our subscribers and sponsors for making it possible to publish this journal in open access, free of charge for authors.

\section{Please help to maintain this journal in open access!}

Check that your library subscribes to the journal, or make a personal donation to the S2O programme, by contacting subscribers@edpsciences.org

More information, including a list of sponsors and a financial transparency report, available at: https://www. edpsciences.org/en/maths-s2o-programme 